\title{
Effect of educational intervention on knowledge and attitude towards research, research ethics, and biobanks among paramedical and administrative teams in the National Liver Institute, Egypt
}

\author{
Sally W. EL-Khadry', Ayat R. Abdallah', Marwa F. Yousef', Hesham M. abdeldayem², Sameera Ezzat ${ }^{\text {** }}$ and
} Laila Shehata Dorgham ${ }^{1}$

\begin{abstract}
Background: Medical research has increased greatly in many developing countries during the recent decade, motivated by the need to improve health in these countries. Such research needs to be guided by fundamental ethical principles to ensure the protection of patient's rights and welfare. Also, biobanks have become increasingly important for the study of health and disease. There is a significant public interest in the outcomes of genetic research, which include diagnostic, therapeutic, and preventive health methods. This study was conducted assess and raise the knowledge and attitude towards several aspects of research, related ethics, and biobank ethical issues for paramedical and administrative teams working at the National Liver Institute (NLI).

Results: The education intervention study was effective in increasing percentage of good knowledge in paramedical and administrative teams ( $p$ value $<0.001$ ). Also, the education intervention study was effective in increasing percentage of positive attitude in paramedical and administrative teams ( $p$ value $<0.001$ ).

Conclusion: There were good knowledge and attitude about research and related ethics, but poor knowledge and attitude about biobanking. The educational intervention study significantly increased knowledge and attitude about research, related ethics, and biobanks.
\end{abstract}

Keywords: Research, Research ethics, Biobank, Paramedical team, Administrative team, Egypt

\section{Background}

The most essential component of a successful research program is developing a well-qualified research staff or team. Clinicians, research nurses, data managers, and study coordinators are an example of research team [1]. Some of their responsibilities are regulatory compliance, protocol maintenance, patient care, tissue acquisition and transmittal, data collection and submission, and general administration. All these tasks are not accomplished by

\footnotetext{
* Correspondence: drsekhir@yahoo.com

'Epidemiology and Preventive Medicine Department, National Liver Institute, Menoufia University, Gamal Abdel Nasser Street, Shebein El-Kom, Menoufia, Egypt

Full list of author information is available at the end of the article
}

individual work, but by collective action and cooperation of all members of the research team, so successful management requires a shared commitment to excellence, mutual respect for each team's role, and effective communication. Once staff are trained and the data management system implemented, this infrastructure must be maintained and continuously updated. Ultimately, an effective leader in research plans must recognize the value of each member while fostering team culture and commitment to quality patient care [1]. More than $30 \%$ of the total time and effort needed to implement a clinical trial research is the contribution of nurses, as well as data manager [2]. This indicates the important role of paramedics (e.g., nurses) and administrative members in doing researches. 
There is a need to improve health in many developing countries, so medical research has grown exponentially in these countries in the last decade [3]. Only 177,824 Egyptian reports were published between 1996 and 2017, compared with the USA with 110,364,243 published documents. However, Egypt ranks 39th in the number of publications between 1996 and 2017 [4]. There were only 669.3 Egyptian researchers per million inhabitants in 2017, while 4673.2 researchers per million inhabitants in the USA and 2407 researchers per million inhabitants in the United Arab Emirates [5].

Because people are involved in medical research, the research should be guided by basic ethical principles to ensure that their rights and well-being are protected. In addition, international standards require that research findings be reviewed by the research ethics committees (RECs) [6].

Biobanks are becoming increasingly important for health and disease research. The public interest in the results of research and genetic research, including methods and products for diagnosis, therapy, and preventive health, is also high [7]. A full interaction between a wide range of stakeholders involved in the biobank, including the public, patients, health professionals, government, and donors, is important due to the current shift to precision medicine [8]. The survival of biobanks and genetic research need a public support, understanding, and active participation [9].

The main objective of the current study was to assess and raise the knowledge and attitude about research, research ethics, biobanks, and their willingness to donate biospecimens among paramedical as well as administrative teams working at NLI, Menoufia University, Egypt.

\section{Methods}

\section{Ethical point of research}

- Firstly, the study protocol was submitted to get approval from the Research Ethics Review committee at National Liver institute (NLI) (IRB00003413), Menoufia University.

- Written consent was taken from the participating subjects in the study for answering the questionnaire after being informed of the full details of the research including risks and benefits.

- Confidentiality of the information was assured.

\section{Study design}

This study was divided into two parts: the first is crosssectional study and the second is a quasi-experiment pretest-posttest design study which was conducted at the National Liver Institute (NLI) during the period from 1 May 2017 to the end of July 2019. The number of participants included in this study was 185 participants; 70 paramedics (nurses, X-ray technicians, and laboratory personnel) and 115 administrative participants of both sex and any age. Firstly, all of the participants had a discussion about the objectives and all details about the study before they gave their written consent. Secondly, they were assessed about knowledge, attitude towards several aspects of research, and research ethics and biobanking through pre-designed self-administered questionnaire in Arabic language (the cross-sectional study). Thirdly, implementing an interventional educational study was done through lectures and handouts. The lectures content included the following: (1) importance, definition, importance, and characteristics of research; (2) definition, importance, and guiding principles of research ethics; and (3) definition, importance, sampling, donors, and biobank privacy. Also, lectures and meeting emphasized the importance of research team and the main role of paramedic and administrative teams in doing any research.

This interventional educational study day was repeated six times which is about research and its importance, research ethics with its guiding principles, and biobanks and how to encourage donation and inform general population to it. Finally, Re-assessment of knowledge and attitude towards several aspects of Research, Research ethics, and biobanking through the same questionnaire after three months of the intervention study in order to make sure the information is clear and to evaluate the effect of the intervention study with the delivery of certificates to those who completed the course and handed over questionnaires.

\section{Data collection and scoring}

A pre-designed self-administered Arabic language questionnaire was used after validation and reliability. Validation was done by submitting it to a panel of four experts to test its validity; the experts were two professors, 1 assistant professor, and 1 lecturer of community specialties, and the experts reviewed the tool for content accuracy and internal validity. Also, professors were asked to judge the items for completeness and clarity (content validity). Suggestions were incorporated into the tool. Test-retest reliability was applied by the researcher for testing the internal consistency of the study tools. It was done through the administration of the same participants under similar conditions on two occasions 1 week apart. The tools' reliability has been verified with Cronbach's $\alpha$ values of 0.70 .

The questionnaire included three sections: the first is to collect data about socio-demographic characters and the other two sections to measure knowledge and attitude regarding research, research ethics, and biobanks. The knowledge scale consists of 13 items using a 2-point Likert-type scale: 1 for correct answer and 0 for do not know or wrong answer. The total knowledge score 
ranged from 0 to 13 . The knowledge was considered good if percentages of knowledge score were more than $70 \%$ and poor knowledge if percentage was equal to or less than $70 \%$. The attitude scale consists of 13 items using a 3-point Likert-type scale (agree, neither agree nor disagree, disagree) to measure attitudes about research, research ethics, and biobanks. The scale includes both positively and negatively worded items: 2 for positive attitudes, 1 for neither agree nor disagree, and 0 for negative attitudes. The total attitude score ranged from 0 to 26 . The attitude was considered positive if percentages of attitude score were more than $70 \%$ and negative if percentage was equal to or less than $70 \%$.

\section{Statistical analysis}

Results were collected, tabulated, and statistically analyzed by an IBM-compatible personal computer with SPSS statistical package version 22. Data were shown as mean, range or value, and frequency and percent. Descriptive statistics, e.g., number (no), percentage (\%), mean $\left(X^{-}\right)$, and standard deviation (SD). Tests of normality distribution were done by Kolmogorov-Smirnova test and Shapiro-Wilk test for all quantitative data. McNemar test was used to study the association between paired qualitative variables. Wilcoxon test was be used to compare the mean and SD of paired quantitative not normally distributed data. $p$ value of $<$ 0.05 was considered statistically significant.

\section{Results}

The majority of paramedical and administrative teams were females ( $85.7 \%$ and $67.8 \%$ respectively); their mean age was $31.9 \pm 10.8$ and $41.6 \pm 8.8$ years, and most of them had B.A. (57.1\% and $60 \%$ respectively). Approximately three quarters of studied paramedical and administrative team had no enough income $(75.7 \%$ and $73 \%$ respectively) (Table 1 ).

The results demonstrate that only $18.6 \%$ and $13.9 \%$ of paramedical team and administrative teams respectively had a previous participation in a scientific research, and $94.3 \%$ and $85.3 \%$ of them respectively knew that scientific research is important in helping to serve patients. However, only $34.3 \%$ and $40.9 \%$ of paramedical team and administrative teams respectively knew by the presence of the National Liver Institute Research Ethics Committee. Also, only $22.9 \%$ and $27 \%$ of them respectively knew that there is a biobank at the National Liver Institute (Table 2).

The education intervention study for the paramedical team had a high significant increase of mean total knowledge score post-intervention $(12.2 \pm 0.5)$ than preintervention $(7.8 \pm 2.4)(p$ value $<0.001)$, as the

Table 1 Sociodemographic data of paramedical and administrative team of our studied participant at the National Liver Institute of Menoufia University

\begin{tabular}{|c|c|c|c|c|c|c|}
\hline \multirow[t]{2}{*}{ Demographic criteria } & \multicolumn{2}{|c|}{ Paramedical (70) } & \multicolumn{2}{|c|}{ Administrative team $(N=115)$} & \multicolumn{2}{|c|}{ Total $(N=185)$} \\
\hline & No & $\%$ & No & $\%$ & No & $\%$ \\
\hline \multicolumn{7}{|l|}{ Sex } \\
\hline Male & 10 & 14.3 & 37 & 32.2 & 47 & 25.4 \\
\hline Female & 60 & 85.7 & 78 & 67.8 & 138 & 74.6 \\
\hline \multicolumn{7}{|l|}{ Age (years) } \\
\hline Mean \pm SD & \multicolumn{2}{|c|}{$31.9 \pm 10.8$} & \multicolumn{2}{|c|}{$41.6 \pm 8.8$} & \multicolumn{2}{|c|}{$38.2+10.57$} \\
\hline Median (range) & \multicolumn{2}{|c|}{$27.5(21-59)$} & \multicolumn{2}{|c|}{$40.5(22-59)$} & \multicolumn{2}{|c|}{$40(21-59)$} \\
\hline \multicolumn{7}{|l|}{ Education } \\
\hline Health technical institution & 21 & 30 & - & - & 21 & 11.4 \\
\hline Secondary education or equivalent & 8 & 11.4 & 42 & 36.5 & 50 & 27 \\
\hline University education & 40 & 57.1 & 69 & 60 & 109 & 58.9 \\
\hline Master and PhD & 1 & 1.4 & 4 & 3.5 & 5 & 2.7 \\
\hline \multicolumn{7}{|l|}{ Job } \\
\hline Nursing & 41 & 58.6 & - & - & 41 & 22.2 \\
\hline Technician & 29 & 41.4 & - & - & 115 & 62.2 \\
\hline Employee & - & - & 115 & 100 & 29 & 15.7 \\
\hline \multicolumn{7}{|l|}{ Income status } \\
\hline Not enough & 53 & 75.7 & 84 & 73 & 137 & 74.1 \\
\hline Enough & 17 & 24.3 & 30 & 26.1 & 47 & 25.4 \\
\hline More than enough & 0 & 0 & 1 & 0.9 & 1 & 0.5 \\
\hline
\end{tabular}


Table 2 Research, related ethics, and biobank knowledge of the studied paramedical and administrative team participants, preintervention

\begin{tabular}{|c|c|c|c|c|c|c|c|c|c|c|c|c|}
\hline \multirow[t]{3}{*}{ Research, research ethics, and biobank knowledge items } & \multicolumn{6}{|c|}{ Paramedical $(N=70)$} & \multicolumn{6}{|c|}{ Administrative team $(N=115)$} \\
\hline & \multicolumn{2}{|c|}{ Yes } & \multicolumn{2}{|l|}{ No } & \multicolumn{2}{|c|}{$\begin{array}{l}\text { Do not } \\
\text { know }\end{array}$} & \multicolumn{2}{|l|}{ Yes } & \multicolumn{2}{|l|}{ No } & \multicolumn{2}{|c|}{$\begin{array}{l}\text { Do not } \\
\text { know }\end{array}$} \\
\hline & $N$ & $\%$ & $N$ & $\%$ & $N$ & $\%$ & $N$ & $\%$ & N & $\%$ & $N$ & $\%$ \\
\hline 1. Previous participation in a scientific research.( yes) & 13 & 18.6 & 57 & 81.4 & 0 & 0.0 & 16 & 13.9 & 99 & 86.1 & 0 & 0.0 \\
\hline \multicolumn{13}{|l|}{ Scientific research is important in: } \\
\hline 2. Raising the degree in job (yes) & 63 & 90 & 7 & 10.0 & 0 & 0.0 & 95 & 82.6 & 18 & 15.7 & 2 & 1.7 \\
\hline 3. Discovering a new treatment for diseases (yes) & 56 & 80 & 12 & 17.1 & 2 & 2.9 & 94 & 81.7 & 18 & 15.7 & 3 & 2.6 \\
\hline 4. Contributing in the development of communities( yes) & 63 & 90 & 7 & 10.0 & 0 & 0.0 & 102 & 88.7 & 13 & 11.3 & 0 & 0.0 \\
\hline 5. Helping to serve patients( yes) & 66 & 94.3 & 4 & 5.7 & 0 & 0.0 & 98 & 85.2 & 10 & 8.7 & 7 & 6.1 \\
\hline 6. There is no obvious importance to scientific research ( no) & 54 & 77.1 & 13 & 18.6 & 3 & 4.3 & 37 & 32.2 & 78 & 67.8 & 0 & 0.0 \\
\hline 7. Presence of the National Liver Institute research ethics committee ( yes) & 17 & 24.3 & 30 & 42.8 & 23 & 32.9 & 47 & 40.9 & 58 & 50.4 & 10 & 8.7 \\
\hline 8. Doing a research on patient or use their data without their permission (no) & 6 & 8.6 & 64 & 91.4 & 0 & 0.0 & 30 & 26.1 & 82 & 71.3 & 3 & 2.6 \\
\hline 9. Knowing biobanks (yes) & 15 & 21.4 & 48 & 68.6 & 7 & 10.0 & 31 & 27 & 50 & 43.4 & 34 & 29.6 \\
\hline 10. Biobanks are useful for science, scientific research, and society ( yes) & 28 & 40 & 32 & 50.0 & 7 & 10.0 & 46 & 40 & 49 & 42.6 & 20 & 17.4 \\
\hline 11. Patients are the only donors to biobanks ( no) & 41 & 58.6 & 26 & 37.1 & 3 & 4.3 & 60 & 52.2 & 41 & 35.6 & 14 & 12.2 \\
\hline 12. Taking blood or urine samples from the patient without his knowledge (no) & 5 & 7.1 & 65 & 92.9 & 0 & 0.0 & 14 & 12.2 & 101 & 87.8 & 0 & 0.0 \\
\hline 13. Presence of a biobank at the National Liver Institute (yes) & 16 & 22.9 & 30 & 42.8 & 24 & 34.3 & 31 & 27 & 64 & 55.6 & 20 & 17.4 \\
\hline
\end{tabular}

Correct answers are in italics, and the most frequent answers are in boldface

education intervention study was effective in decreasing percentage of poor knowledge from $78.6 \%$ preintervention to $0 \%$ post-intervention and in increasing percentage of good knowledge from $21.4 \%$ preintervention to $100 \%$ post-intervention, and this effect was highly statistically significant ( $p$ value $<0.001$ ). Also, the education intervention study for the administrative team had a high significant increase of mean total knowledge score post-intervention $(12.1 \pm 0.5)$ than preintervention $(7.5 \pm 2.7)$ ( $p$ value $<0.001)$. Also, the education intervention study was effective in decreasing percentage of poor knowledge from $78.3 \%$ pre-intervention to $0.9 \%$ post-intervention and in increasing percentage of good knowledge from $21.7 \%$ pre-intervention to $99 \%$ post-intervention, and this effect was highly statistically significant $(p$ value $<0.001)$ (Fig. 1).

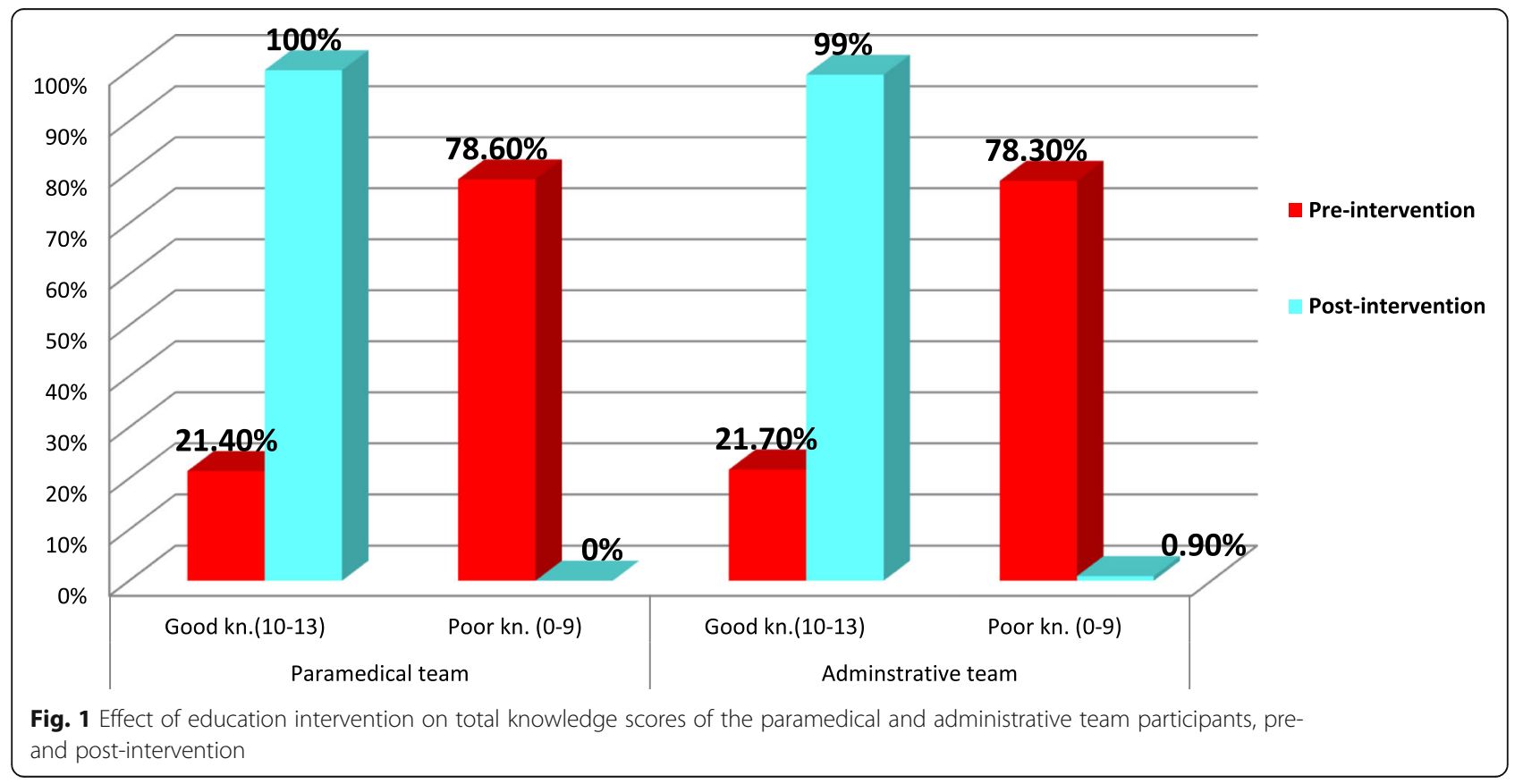


The results demonstrated a high percent positive attitude in most of attitude items for the paramedical and administrative team participants: $91.4 \%$ of paramedical team participants had positive attitude to "patients' outcomes improve with continuing medical research," while 77.4\% for the administrative team; $92.9 \%$ of paramedical team participants had positive attitude to "Ethics Committee of Scientific Research is useful," while $86.1 \%$ for the administrative team; and $91.4 \%$ of paramedical team participants had positive attitude to "research should be reviewed for ethical standards before completion of the research," while $87 \%$ for the administrative team. However small percentage of $40 \%$ of the paramedical team participants had positive attitude to "helping in collection of samples for a biobank" while $36.6 \%$ for the administrative team, and $38.6 \%$ of paramedical team participants had positive attitude to "giving a samples to a biobank," while $35.7 \%$ for the administrative team (Table 3).

The education intervention study for paramedical team had a high significant increase of mean total attitude score post-intervention $(25.3 \pm 0.9)$ than preintervention $(21.6 \pm 2.4)$ ( $p$ value $<0.001)$, as the education intervention study was effective in decreasing percentage of negative attitude from $10 \%$ pre-intervention to $0 \%$ post-intervention and in increasing percentage of positive attitude from $90 \%$ pre-intervention to $100 \%$ post-intervention, and this effect was highly statistically significant ( $p$ value $<0.001$ ). Also, the education intervention study for administrative team had a high significant increase of mean total attitude score postintervention $(25.5 \pm 0.8)$ than pre-intervention $(20.7 \pm$ 3.3) ( $p$ value $<0.001$ ), as the education intervention study was effective in decreasing percentage of negative attitude from $21.7 \%$ pre-intervention to $0 \%$ postintervention and in increasing percentage of positive attitude from $78.3 \%$ pre intervention to $100 \%$ postintervention, and this effect was highly statistically significant ( $p$ value $<0.001$ ) (Fig. 2).

\section{Discussion}

Very small articles were published to assess research and related ethics knowledge of paramedical personnel, and specifically, participants were nurses only. In addition, no previous studies had been conducted for administrative team. So, the present study was done on paramedical and administrative teams working at NLI for assessing and rising knowledge and attitude about research, related ethics, and biobanks by educational intervention.

Regarding research participation and knowledge of the study participants, only $18.6 \%$ and $13.9 \%$ of paramedical team and administrative teams respectively had a previous participation in a scientific research which is considered to be low participation. This was in contrast with Abouelfettoh and Al Ateeq's study where 31.2\% (206/ 660) of paramedical nurses had a previous participation on a research [10]. This difference may be due to the fact that in current study paramedical team included technicians who were not interested in doing medical

Table 3 Research, research ethics, and biobank attitude of the studied paramedical and administrative team participants, preintervention

\begin{tabular}{|c|c|c|c|c|c|c|c|c|c|c|c|c|}
\hline & \multicolumn{6}{|c|}{ Paramedical (70) } & \multicolumn{6}{|c|}{ Administrative team $(N=115)$} \\
\hline & \multicolumn{2}{|c|}{ Agree } & \multicolumn{2}{|c|}{ Fair } & \multicolumn{2}{|c|}{$\overline{\text { Disagree }}$} & \multicolumn{2}{|c|}{ Agree } & \multicolumn{2}{|l|}{ Fair } & \multicolumn{2}{|c|}{$\overline{\text { Disagree }}$} \\
\hline & $N$ & $\%$ & $N$ & $\%$ & $N$ & $\%$ & $N$ & $\%$ & $N$ & $\%$ & $N$ & $\%$ \\
\hline 14. Patients' outcomes improve with continuing medical research. & 64 & 91.4 & 6 & 8.6 & 0 & 0 & 89 & 77.4 & 25 & 21.7 & 1 & 0.9 \\
\hline 15. The employee should be trained in scientific research and was mandatory. & 43 & 61.4 & 26 & 37.1 & 1 & 1.4 & 83 & 72.2 & 31 & 27 & 1 & 0.9 \\
\hline 16. Participation in future scientific research. & 57 & 81.4 & 13 & 18.6 & 0 & 0 & 75 & 65.2 & 32 & 27.8 & 8 & 7 \\
\hline 17. Ethics Committee of Scientific Research is useful. & 65 & 92.9 & 5 & 7.1 & 0 & 0 & 99 & 86.1 & 16 & 13.9 & 0 & 0 \\
\hline $\begin{array}{l}\text { 18. Research should be reviewed for ethical standards before completion of } \\
\text { the research. }\end{array}$ & 64 & 91.4 & 6 & 8.6 & 0 & 0 & 100 & 87 & 15 & 13 & 0 & 0 \\
\hline 19. Research ethics should be taught as a mandatory university unit. & 53 & 75.7 & 15 & 21.4 & 2 & 2.9 & 90 & 78.3 & 25 & 21.7 & 0 & 0 \\
\hline $\begin{array}{l}\text { 20. Patients should be informed of the full details of the research including risks } \\
\text { and benefits and written consent. }\end{array}$ & 59 & 84.3 & 6 & 8.6 & 5 & 7.1 & 84 & 73 & 20 & 17.4 & 11 & 9.6 \\
\hline 21. Helping in collection of samples for a biobank. & 28 & 40 & 42 & 60 & 0 & 0 & 42 & 36.6 & 61 & 53 & 12 & 10.4 \\
\hline 22. People who provide vital samples help diagnose diseases & 33 & 47.1 & 36 & 51.4 & 1 & 1.4 & 60 & 52.2 & 54 & 47 & 1 & 0.9 \\
\hline 23. People who give vital samples help prevent diseases & 26 & 37.1 & 42 & 60 & 2 & 2.9 & 51 & 44.3 & 56 & 48.7 & 8 & 7 \\
\hline 24. Giving biological sample is for the greater good of society. & 41 & 58.6 & 29 & 41.4 & 0 & 0 & 64 & 55.7 & 50 & 43.5 & 1 & 0.9 \\
\hline 25. Giving samples to a biobank. & 27 & 38.6 & 34 & 48.6 & 9 & 12.9 & 41 & 35.7 & 59 & 51.3 & 15 & 13 \\
\hline 26. Assisting in the collection of samples for the NLI biobank. & 63 & 90 & 5 & 7.1 & 2 & 2.9 & 75 & 65.2 & 36 & 31.3 & 4 & 3.5 \\
\hline
\end{tabular}

Positive attitude answers are in italics, and the most frequent answers are in boldface 


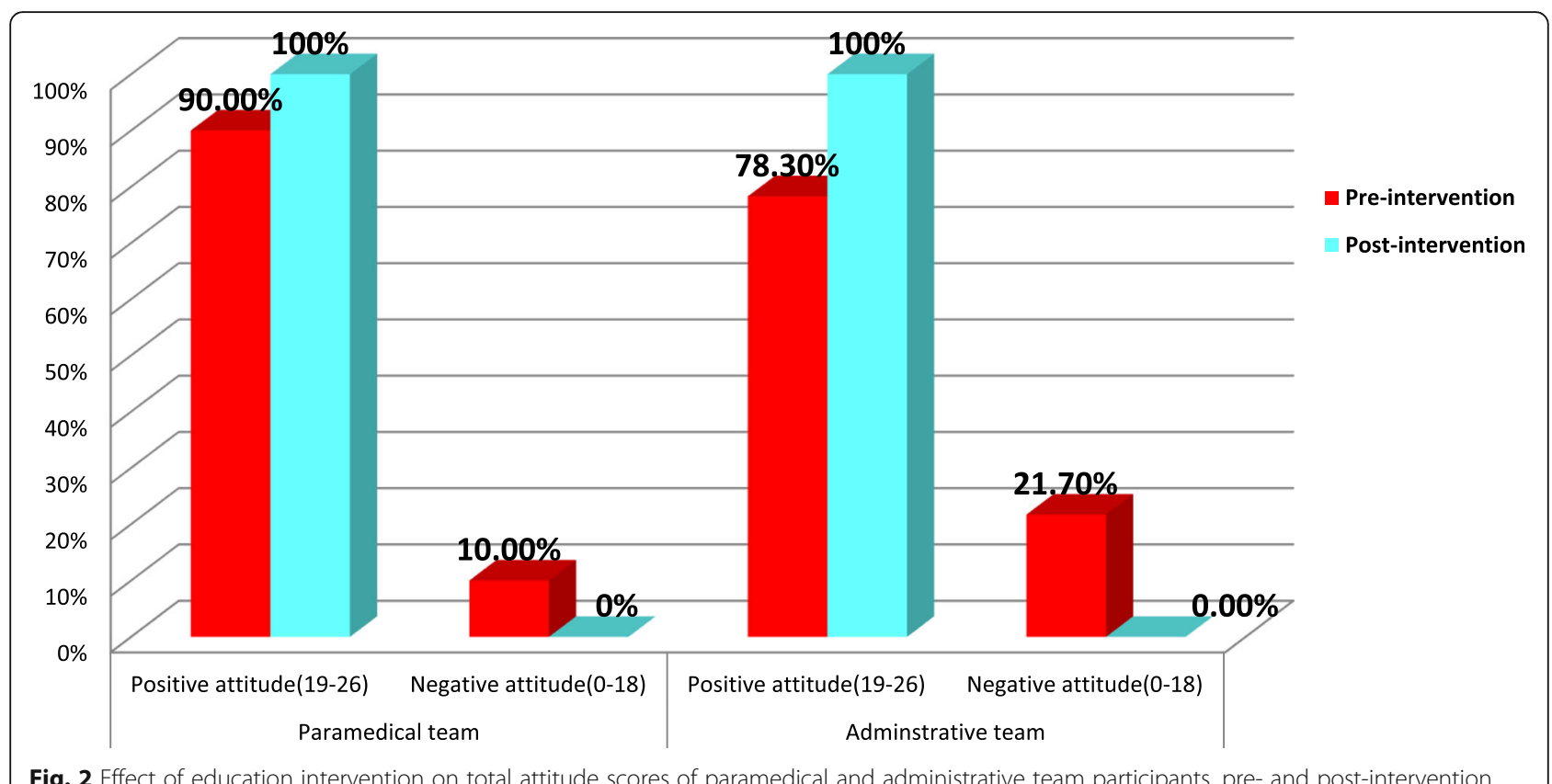

Fig. 2 Effect of education intervention on total attitude scores of paramedical and administrative team participants, pre- and post-intervention

research and nurses who were not yet involved in medical research and had no sufficient opportunities for involving in research.

In the present study, $94.3 \%$ and $85.3 \%$ of the paramedical team and administrative teams respectively knew that scientific research is important in helping to serve patients which was a high level of knowledge in comparative to Abouelfettoh and Al Ateeq's study where nurses' knowledge about research were moderate [10]. This indicates that the NLI paramedical and administrative teams need only opportunity to participate in a research with their high knowledge about research importance.

Regarding research ethics knowledge of the study participants, more than $90 \%$ of the paramedical team and two thirds of the administrative team knew about research ethics and knew that doing a research on patient or use their data without their permission is not ethical or permissible. This result was in agreement with Adhikari et al.'s study where $96.5 \%$ of nurses knew the importance of confidentiality and patient data security [11] and also in Aliyu et al.'s study where the majority of the nurse participants $(82.6 \%, 114$ out of 138 ) possess good knowledge of ethical dilemma [12].

Regarding biobank knowledge of the study participants, unfortunately, only $34.3 \%$ and $40.9 \%$ of the paramedical team and administrative team respectively knew the presence of the National Liver Institute Research Ethics Committee. This may be due to the low participation in research.

Also, only very small percentage of paramedical and administrative teams knew about biobanks and that there is a biobank at the National Liver Institute. This result was in agreement with Eisenhauer's study in which the overall knowledge scores were very low [13] and also in Igbe and Adebamowo's study in Nigeria; the participants had limited knowledge of biobanking and its implications [14]. It has the same results as Ahram et al.'s study [15]. This limited knowledge may be due to the field of biobanking being new with no good public dissemination.

Regarding the education intervention study and knowledge for participants, in the current study, the mean total knowledge scores about research, ethics, and biobank preintervention for paramedical and administrative teams were $7.8 \pm 2.4$ and $7.5 \pm 2.7$ respectively (out of 13 total score). Actually, intervention education study had a significant increase in mean total knowledge scores for both group post-intervention as $12.2 \pm 0.5$ for the paramedical team and $12.1 \pm 0.5$ for the administrative team.

Fortunately, at the current study, the paramedical education intervention study was highly effective in increasing percentage of good knowledge from $21.4 \%$ preintervention to $100 \%$ post-intervention, and this effect was highly statistically significant $(p$ value $<0.001)$. In addition, the administrative team education intervention study was highly effective in increasing percentage of good knowledge from $21.7 \%$ pre-intervention to $100 \%$ post-intervention, and this effect was highly statistically significant $(p$ value $<0.001)$, which were very impressive results suggesting more and more intervention educations to raise their knowledge.

Regarding research attitude of the study participants, more than $90 \%$ of the paramedical team and three 
quartiles of the administrative team had positive attitude towards continuous medical research. This result was with more positive attitude than Abouelfettoh and $\mathrm{Al}$ Ateeq's study in which nurses' attitude levels were moderate [10]. Nearly two thirds of the study participants agreed that the employee should be trained in scientific research and nearly three quartiles agreed to participate in research in the future which is indicating good positive attitude towards research.

Regarding research ethics attitude of the study participants, three quartiles of the study participants (paramedical and administrative teams) agreed that research ethics should be taught as a mandatory university course. Also, most of the study participants $(92.9 \%$ of paramedical and 86.1\% of administrative teams) agreed that the Ethics Committee of Scientific Research is useful. This was in agreement with Adhikari et al. study where $98.8 \%$ nurses ( 85 out of 86 ) agreed that ethics course should be taught in every medical/nursing teaching institution [11].

At the present study, $84.3 \%$ of paramedical and $73 \%$ of administrative teams agreed that patients should be informed of the full details of the research including risks and benefits and written consent. This was in agreement with Adhikari et al.'s study where $89.5 \%$ of nurses agreed that consent is not only for surgeries and it is for any intervention, as well as Aliyu et al.'s study where the majority $(83 \%, 116$ out of 140$)$ of the nurse participants admitted that consent should be obtained for both operations and nursing procedure [12].

Regarding biobanks attitude of the study participants, only $47.1 \%$ of the paramedical and $52.2 \%$ of the administrative team agreed to provide vital sample to help in the diagnosis of diseases in a biobank; also, only $40 \%$ of the paramedical and $36.6 \%$ of the administrative teams agreed to help in the collection of samples for a biobank. This is in contrast to Alzoubi's study where there was overwhelming support (>85\%) for the establishment of biobanks in Jordan, and most of the participants agreed on the importance of biobanks and sample donation in promoting medical research [16]. Also, all of interviewees were willing to share their blood sample or donate it to biobank for future use in Sakulthaew et al.'s study, and in Igbe and Adebamowo's study, the majority of the participants were willing to participate in biobank research for non-communicable diseases [14, 17]. Biobank attitude of the study participants had less positive attitude than research and research ethics attitude; this may be due to their less knowledge about biobanking. But fortunately, $90 \%$ of nurses and $65.2 \%$ of administratives agreed to assist in the collection of samples for the NLI biobank.

Regarding the education intervention study and attitude for participants, in the current study, the mean total attitude score about research, ethics, and biobank pre-intervention for paramedical and administrative teams were $21.6 \pm 2.4$ and $20.7 \pm 3.3$ respectively (out of 26 total score).

Actually, intervention education study had a significant increase in the mean total attitude scores for both groups post-intervention as $25.3 \pm 0.9$ for the paramedical team and $25.5 \pm 0.8$ for the administrative team.

Fortunately, at the current study, the paramedical team education intervention study was highly effective in increasing the percentage of positive attitude from $90 \%$ pre-intervention to $100 \%$ post-intervention, and this effect was highly statistically significant ( $p$ value $<0.001$ ) Also, the administrative team education intervention study was highly effective in increasing the percentage of positive attitude from $78.3 \%$ pre-intervention to $100 \%$ post-intervention, and this effect was highly statistically significant ( $p$ value $<0.001)$.

\section{Conclusion}

To the best of our knowledge, this study is the first to evaluate and elevate knowledge and attitude towards research, related ethics, and biobanks among paramedical and administrative teams.

Our study shows that there were good knowledge and attitude about research and related ethics, but insufficient knowledge and attitude about biobanking. However, fortunately, the educational intervention study significantly increased knowledge and attitude about research, related ethics, and biobanks. These approaches have the potential to build trust, including providing a venue to address common concerns about research, related ethics, and biobanks.

\section{Recommendation}

There is a need for more training and time spent in the Menoufia University on research methods, related ethics, and biobanking intervention education workshops or training for paramedical and administrative team participants. There is also a need to do further studies in other Egyptian universities and other Middle Eastern medical schools. The findings of this study may guide future development and improvement of training or workshop to put more emphasis on building research skills, ethics, and biobanks. There is a need for adding research methodology, research ethics, and biobanking as a curriculum in nursing faculties for enriching their knowledge.

\section{Limitation of study}

Due to the too busy schedule of administrative and paramedical participants, they were reluctant for attending intervention education study. Six education intervention days were held to overcome this limitation. 


\section{Abbreviations}

NLI: National Liver Institute; RECs: Research ethics committees

\section{Acknowledgements}

Not applicable

\section{Declarations}

Our study was totally designed by the authors including the method of study, the questionnaire, and also the intervention education material lectures and booklet which were formulated by the authors.

\section{Authors' contributions}

SW collected, analyzed, and interprited the study data and contributed to the manuscript writing. AR and MF contributed to the manuscript writing. SE and $\mathrm{HM}$ contributed to the manuscript writing and supervision of the intervention study. SE and LD were the major contributors to the manuscript writing and revising. All authors read and approved the final manuscript.

\section{Funding}

This study was self-funded.

\section{Availability of data and materials}

The dataset of the current study is available from the corresponding author on reasonable request.

\section{Ethics approval and consent to participate}

The research ethics review committee of National Liver Institute Menoufia University (IRB00003413) approved the study regarding confidentiality and the written consent with approval number (000169). The researcher introduced herself to the participants in the sample and explained the objectives of the study to obtain their acceptance to be recruited in the study as well as to gain their cooperation by applying the consent form before the questionnaire.

\section{Consent for publication}

Not applicable.

\section{Competing interests}

The authors declare that they have no competing interests.

\section{Author details}

${ }^{1}$ Epidemiology and Preventive Medicine Department, National Liver Institute, Menoufia University, Gamal Abdel Nasser Street, Shebein El-Kom, Menoufia, Egypt. ${ }^{2}$ Hepatobilary Surgery Department, National Liver Institute, Menoufia University, Menoufia, Egypt.

Received: 25 September 2019 Accepted: 12 November 2019 Published online: 03 January 2020

\section{References}

1. Baer AR, Zon R, Devine S, Lyss AP (2011) The clinical research team. J Oncol Pract. https://doi.org/10.1200/jop.2011.000276

2. Emanuel EJ, Schnipper LE, Kamin DY, Levinson J, Lichter AS (2003) The costs of conducting clinical research. J Clin Oncol. https://doi.org/10.1200/JCO. 2003.08.156

3. Normile D (2008) The promise and pitfalls of clinical trials overseas. Science. https://doi.org/10.1126/science.322.5899.214

4. SJR - International Science Ranking. https://www.scimagojr.com/ countryrank.php. Published 2019. Accessed May 162019.

5. Researchers in R\&D (per million people) https://data.worldbank.org. https:// data.worldbank.org/indicator/SP.POP.SCIE.RD.P6?end=2017\&locations= $E G \& s t a r t=2007$. Published 2019. Accessed May 162019.

6. Council for International Organizations of Medical Sciences, World Health Organization. International Ethical Guidelines for Health-Related Research Involving Humans 2016.

7. Lemmens T, Austin LM. The end of individual control over health information: promoting fair information practices and the governance of biobank research. 2009. https://papers.ssin.com/sol3/papers.cfm?abstract id=1337695. Accessed 2 Nov 2018.
8. Manolio TA, Abramowicz M, Al-Mulla F et al (2015) Global implementation of genomic medicine: We are not alone. Sci Transl Med. https://doi.org/10. 1126/scitransImed.aab0194

9. Dry SM, Garrett SB, Koenig BA et al (2017) Community recommendations on biobank governance: results from a deliberative community engagement in California. PLoS One. https://doi.org/10.1371/journal.pone. 0172582

10. Abouelfettoh A, Al Ateeg E. Nurses ' KAP related to research conduct and utilization: EBNP " are we ready yet .2018 doi:https://doi.org/10.14419/ijans V7i1.11814

11. Adhikari S, Paudel K, Aro AR, Adhikari TB, Adhikari B, Mishra SR (2016) Knowledge, attitude and practice of healthcare ethics among resident doctors and ward nurses from a resource poor setting, Nepal. BMC Med Ethics. 17(1):1-8. https://doi.org/10.1186/s12910-016-0154-9

12. Aliyu D, Adeleke IT, Omoniyi SO. Knowledge, attitude and practice of nursing ethics and law among nurses at Federal Medical Centre, Bida. 2014; (January 2015). doi:10.11648/j.ajhr.s.2015030101.15

13. Eisenhauer ER. Informed choices in biobanking: an examination of participants' understanding and congruence between knowledge, values, and decisions. A Diss Submitt Partial fulfillment Requir degree Dr Philos Univ Michigan. 2018. doi:https://doi.org/10.1590/s1809-98232013000400007

14. Igbe MA, Adebamowo CA (2012) Qualitative study of knowledge and attitudes to biobanking among lay persons in Nigeria. BMC Med Ethics. 13(1):27. https://doi.org/10.1186/1472-6939-13-27

15. Ahram M, Othman A, Shahrouri M (2012) Public perception towards biobanking in Jordan. Biopreserv Biobank. https://doi.org/10.1089/bio. 2012.0010

16. Makhlouf H, Alrabadi N, OF K, Alzoubi KH, Al-Delaimy W (2019) Population ' $s$ perspectives toward biobanks in scientific research: a study from Jordan. Pharmgenomics Pers Med.:23-32

17. Sakulthaew $T$, Rungsihirunrat $K$, Cheah $P Y$, et al. Assessing the attitudes and understanding of clinical trial participants in thailand to biobanking. 2016; 30(1):9-17. doi:10.14456/jhr.2016.2

\section{Publisher's Note}

Springer Nature remains neutral with regard to jurisdictional claims in published maps and institutional affiliations.

\section{Submit your manuscript to a SpringerOpen ${ }^{\circ}$ journal and benefit from:}

- Convenient online submission

- Rigorous peer review

- Open access: articles freely available online

High visibility within the field

- Retaining the copyright to your article

Submit your next manuscript at $\boldsymbol{\nabla}$ springeropen.com 